\title{
Oviposition and Immature Development of the Parasitoid Fly Compsilura concinnata (Meigen) (Diptera: Tachinidae)
}

\author{
Ryoko ICHIKI* and Satoshi NAKAMURA \\ Crop Production and Environment Division, Japan International Research Center for Agricultural \\ Sciences (JIRCAS) (Tsukuba, Ibaraki 305-8686, Japan)
}

\begin{abstract}
Compsilura concinnata is a gregarious tachinid which lays eggs directly into a host larva with a sickleshaped ovipositor. The oviposition and immature development of $C$. concinnata was examined using the noctuid moth Mythimna separata as a host. C. concinnata females usually laid one egg per single ovipositional attack, but occasionally laid more than one egg at a time. Also, the females often deposited no eggs in both moving and non-moving hosts, suggesting that this imperfect oviposition was not caused by the defense behaviour of the host. Successful development from egg to adult was obtained within a temperature range of $15.0-27.5^{\circ} \mathrm{C}$. At $30^{\circ} \mathrm{C}$, this fly could pupariate but failed to emerge as an adult. The developmental time from oviposition to adult emergence decreased with rising temperature. The lower developmental threshold from oviposition to adult emergence was $7.7^{\circ} \mathrm{C}$ for females and $8.7^{\circ} \mathrm{C}$ for males. The total effective temperature from oviposition to adult emergence was 404.4 degreedays for females and 342.1 degree-days for males.
\end{abstract}

Discipline: Insect pest

Additional key words: immature survival, Mythimna separata, natural enemy, Noctuidae, tachinid

\section{Introduction}

The tachinid fly, Compsilura concinnata (Meigen), is a polyphagous parasitoid. This tachinid parasitizes over 100 species in the Palearctic Region ${ }^{12}$, at least 161 species in North America ${ }^{1}$, and 67 species in Japan ${ }^{25}$. Most of the hosts are lepidopteran larvae including the noctuid moth Mythimna separata Walker and the gypsy moth Lymantria dispar (Linnaeus), but some sawflies and even coleopterons serve as their hosts. Since the early 1900's, C. concinnata was introduced into North America as a biological control agent for lepidopteran pests, especially L. dispar ${ }^{6}$. Recently, however, some researches pointed out that $C$. concinnata damages the populations of native and nontarget lepidopteran species in introduced areas ${ }^{2,14,19}$. As well as being a biological control agent, $C$. concinnata is also a critical invading alien species. Although this parasitoid is an important species in both applied entomology and conservation biology, its fundamental biology is poorly studied. C. concinnata is multivoltine ${ }^{7}$, but its lifehistory characteristics including the lower developmental threshold $\left(T_{0}\right)$ and the total effective temperature $(K)$ are unknown. The $T_{0}$ and $K$ are essential parameters for the population dynamics model and useful for selecting natural enemy species for introduction ${ }^{18}$.

In $C$. concinnata, the 7 th abdominal sternum of females develops to form a piercing "ovipositor" 24 . It is unclear how many eggs are laid per single ovipositional attack, since the female lays its eggs directly into the host larva with a sickle-shaped ovipositor. In this study, we first investigated the number of eggs laid by a female per single ovipositional attack to estimate the survival rates of immature stages in C. concinnata. Then, we examined the developmental time, immature survival, size, and sex ratio of adults at different rearing temperatures. In addition we estimated the $T_{0}$ and $K$ of $C$. concinnata.

\section{Materials and methods}

\section{Host and parasitoid}

Larvae of $M$. separata were obtained from a stock culture and reared on an artificial diet using the method of Hattori and Atsusawa ${ }^{11}$. The colony of $C$. concinnata originated from parasitized last-instar larvae of the fall webworm, Hyphantria cunea Drury, which were collected

*Corresponding author: e-mail richiki@mail.goo.ne.jp

Received 13 September 2006; accepted 23 January 2007. 
at Tsukuba, Ibaraki, Japan (lat. $36^{\circ} 2^{\prime} \mathrm{N}$, long. $140^{\circ} 5^{\prime} \mathrm{E}$ ), in September and October 2004. All procedures, except for those in the experiment on the effect of temperature on tachinid development, were conducted at $25^{\circ} \mathrm{C}$ under a photoperiod of $16 \mathrm{~h}$ light (L) : $8 \mathrm{~h}$ dark (D) and $60 \%$ relative humidity $(\mathrm{RH})$.

\section{The number of eggs per single ovipositional attack by $C$. concinnata}

The number of eggs laid by a female fly per single ovipositional attack was investigated by dissection. $M$. separata larvae show aggressive defense behaviour by flicking their heads and vomiting saliva toward parasitoids. The females were sometimes captured by the saliva of the host and not able to fly afterwards. As it is possible that this defense behaviour of host larvae affects the number of eggs laid by a female fly, we compared the number of tachinid eggs laid among the free moving and nonmoving hosts. Six to 8 days after mating, female flies were individually provided with a day 1-2 last instar larva of $M$. separata. A single moving host was placed in a Petri dish $(9.0 \mathrm{~cm} \mathrm{dia.} \times 2.0 \mathrm{~cm}$ depth), along with a single female fly, which was allowed to attack the host only once. In the case of non-moving hosts, the host was held with forceps at the head and thorax. When a host larva was attacked by a C. concinnata female, a small quantity of body fluid usually gushed out from the wound. In both ovipositional experiments, the host was removed immediately after recognizing that bleeding had taken place. The parasitized hosts were dissected $3 \mathrm{~h}$ after oviposition and the number of maggots within the hosts was counted. Five hosts were provided per female. A total of 100 hosts and 20 female flies were used in the experiment of moving hosts, and a total of 50 hosts and 10 female flies were used in the experiment of non-moving hosts.

\section{Effects of temperature on development of $C$. concinnata}

Six to 18 days after mating, female flies were individually provided with a dayl last instar larva of $M$. separata which was able to move freely in a Petri dish. The host was removed immediately after recognizing that bleeding had taken place. The parasitized hosts were individually placed in a Petri dish and provided with an artificial diet for armyworm until the parasitoid larvae emerged from the host. The dishes with parasitized hosts were placed at $15.0,17.5,20.0,22.5,25.0,27.5$, and $30.0^{\circ} \mathrm{C}$ under a photoperiod of 16L: 8D and 60\% RH. Puparial weight, as a parameter of body size, was measured 7 days after puparium formation according to Nakamura ${ }^{22}$. In addition, the developmental time and sex ratio were recorded.

\section{Data analyses}

In this study, 2 or 3 puparia occasionally emerged from a parasitized host, though the female fly was allowed to lay eggs only once. For calculations of survival rates (Table 1), the number of eggs laid by females was estimated as follows: 'estimated number of eggs laid' = 'number of attacks' $\times 0.81$. In this equation, 0.81 was calculated based on the result of the number of eggs per single ovipositional attack in this study: 100 moving host larvae were attacked once by $C$. concinnata, resulting that 81 eggs were laid in total (Fig. 1). To exclude the effect of the multiparasitism on some parameters (developmental

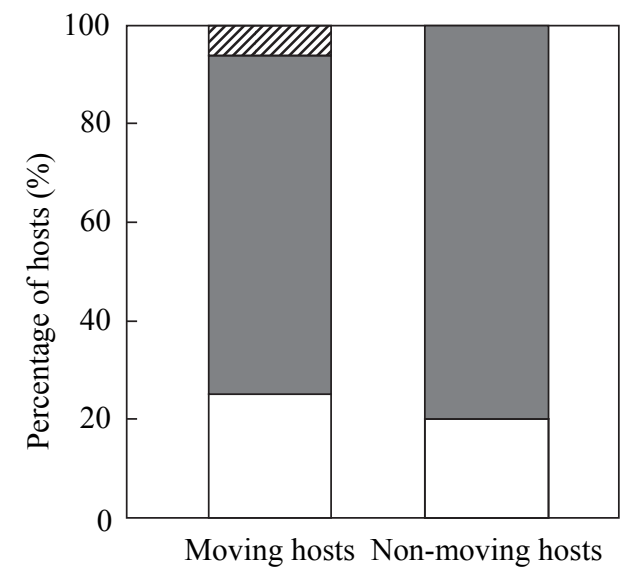

Fig. 1. Number of $C$. concinnata eggs laid by single attack C. concinnata attacked M. separata larva once, and eggs were examined by dissection. Moving host: larva was allowed to move freely. Non-moving host: larva was arrested by holding with forceps. $\mathrm{N}=100$ for the moving hosts, and 50 for the nonmoving hosts.

$\square$ : No egg, $\square$ : One egg, $\mathbb{Z}$ : Two eggs.

Table 1. Survival rates of $C$. concinnata at seven temperatures

\begin{tabular}{ccccc}
\hline \hline $\begin{array}{c}\text { Temperature } \\
\left({ }^{\circ} \mathrm{C}\right)\end{array}$ & $\begin{array}{c}\text { No. of } \\
\text { attacks }\end{array}$ & $\begin{array}{c}\text { Estimated no. } \\
\text { of eggs laid }\end{array}$ & $\begin{array}{c}\% \\
\text { pupariation }\end{array}$ & $\begin{array}{c}\text { \%) adult } \\
\text { emergence }\end{array}$ \\
\hline 15.0 & 59 & 47.8 & 108.8 & 90.0 \\
17.5 & 66 & 53.5 & 108.5 & 73.0 \\
20.0 & 60 & 48.6 & 96.7 & 82.3 \\
22.5 & 75 & 60.8 & 108.6 & 92.2 \\
25.0 & 89 & 72.1 & 102.6 & 92.9 \\
27.5 & 72 & 58.3 & 92.6 & 73.7 \\
30.0 & 58 & 47.0 & 108.6 & 0 \\
\hline
\end{tabular}

a): There was no significant difference in each \% pupariation among the seven temperatures by $\chi^{2}$ test $(P=0.995)$.

b): There was significant difference in each $\%$ adult emergence among the seven temperatures by $\chi^{2}$ test $(P<$ 0.0001). 
times, puparial weights and sex ratio), multiple maggots that emerged from a host were excluded from the data for analyses of these parameters.

Linear regression was performed to analyze developmental rates (the reciprocal of the number of days required for development) as the dependent variable and temperature as the independent variable. Based on the linear regression, the $T_{0}$ and $K$ were estimated.

The developmental time and puparial weights of emerged adults among temperatures were subjected to one-way ANOVA and then compared using Tukey-Kramer test. Inter-sex comparisons of developmental time and puparial weights of emerged adults were made by a $t$-test. The $\chi^{2}$ test was conducted to determine whether or not the survival rates and sex ratios of emerged adults differed among the temperatures. Pearson's correlation coefficient was used to estimate the association between temperature and developmental rate. These statistical analyses were conducted using StatView, version 5.0 (SAS Institute, Cary, NC).

\section{Results}

\section{The number of eggs per single ovipositional attack by $C$. concinnata}

When $C$. concinnata females were provided with $M$. separata larvae, they almost immediately attacked the larvae. When the host larvae were dissected $3 \mathrm{~h}$ after oviposition, all fly eggs had already hatched and the larvae were always found between the peritrophic membrane and the midgut wall of the host. On occasion the larva attached itself posteriorly to host tracheoles of the midgut as described by Ichiki \& Shima ${ }^{16}$. Of the 100 dissected hosts which were able to move freely at oviposition, 69 had 1 larva of the tachinid, 6 had 2 larvae and 25 had no larva within the hosts (Fig. 1). Of 50 hosts which were rendered immovable at oviposition, 40 had 1 larva of the tachinid and 10 had no larva within the hosts.

When the hosts which were attacked by females once were reared at different temperatures, sometimes 2 or 3 puparia egressed from a host. The percentages of 1 puparium per host were highest at all experimental temperatures (range: $51.4-78.7 \%$, mean: $66.2 \%, \mathrm{n}=7$ ). The percentages of 2 puparia per host were $2.2-14.7 \%$ (mean: $7.9 \%, \mathrm{n}=7$ ), and very low percentages of 3 puparia per host emerged at $15^{\circ} \mathrm{C}, 22.5^{\circ} \mathrm{C}$ and $27.5^{\circ} \mathrm{C}$ (range: $0-1.7 \%$, mean: $0.6 \%, n=7$ ). At the 7 temperatures, 17.2 to $30.6 \%$ (mean: $21.9 \%, \mathrm{n}=7$ ) of hosts survived to adult and 0 $6.9 \%$ (mean: $3.3 \%, \mathrm{n}=7$ ) of hosts died but did not produce any puparium.

\section{Immature survival}

Based on the number of eggs per single ovipositional attack, the survival rates were calculated (Table 1). The pupariation rates were $92.6-108.8 \%$ and not significantly different among the seven temperatures of $15-30^{\circ} \mathrm{C}\left(\chi^{2}\right.$ test: $\left.\chi^{2}=0.661, \mathrm{df}=6, P=0.995\right)$. The percentages of adult emergence ranged between $73.0-92.9 \%$ at $15-$ $27.5^{\circ} \mathrm{C}$. At $30^{\circ} \mathrm{C}$, no adult emerged. The survival rates from egg to adult were not significantly different among the six temperatures except $30^{\circ} \mathrm{C}\left(\chi^{2}\right.$ test: $\chi^{2}=1.609, \mathrm{df}=$ $5, P=0.900)$.

\section{Developmental time}

The mean developmental time for each developmental stage from oviposition to adult emergence decreased with rising temperature in both sexes (Tukey-Kramer test, $P<0.05$; Table 2). The developmental time of puparia for

Table 2. Development time of $C$. concinnata at seven temperatures

\begin{tabular}{|c|c|c|c|c|c|}
\hline \multirow{3}{*}{$\begin{array}{c}\text { Temperature } \\
\left({ }^{\circ} \mathrm{C}\right)\end{array}$} & \multicolumn{5}{|c|}{ Developmental time (days) $^{\text {a) }}$} \\
\hline & \multirow[t]{2}{*}{ Eggs and larvae ${ }^{c)}$} & \multicolumn{2}{|c|}{ Puparia ${ }^{b, c)}$} & \multicolumn{2}{|c|}{ Oviposition-adult emergence ${ }^{b, c)}$} \\
\hline & & Females & Males & Females & Males \\
\hline 15.0 & $24.2 \pm 0.8(35) \mathrm{A}$ & $31.7 \pm 0.2(11) \mathrm{aA}$ & $29.9 \pm 0.3(18) \mathrm{bA}$ & $55.4 \pm 1.7(11) \mathrm{aA}$ & $54.3 \pm 1.4(18) \mathrm{aA}$ \\
\hline 17.5 & $15.5 \pm 0.4(50) \mathrm{B}$ & $23.5 \pm 0.2(13) \mathrm{aB}$ & $20.9 \pm 0.2(18) b B$ & $39.8 \pm 1.0(13) \mathrm{aB}$ & $35.5 \pm 0.5(18) b B$ \\
\hline 20.0 & $10.7 \pm 0.1(43) \mathrm{C}$ & $17.6 \pm 0.3(12) \mathrm{aC}$ & $15.9 \pm 0.2(24) b C$ & $28.5 \pm 0.3(12) \mathrm{aC}$ & $26.4 \pm 0.3(24) b C$ \\
\hline 22.5 & $9.0 \pm 0.2(41) \mathrm{D}$ & $14.7 \pm 0.3(15) \mathrm{aD}$ & $13.0 \pm 0.2(18) b D$ & $23.8 \pm 0.4(15) \mathrm{aD}$ & $21.4 \pm 0.2(18) b D$ \\
\hline 25.0 & $8.5 \pm 0.1(70) \mathrm{DE}$ & $13.4 \pm 0.1(36) \mathrm{aE}$ & $12.0 \pm 0.2(27) \mathrm{bE}$ & $22.2 \pm 0.2(36) \mathrm{aD}$ & $20.0 \pm 0.2(27) b D$ \\
\hline 27.5 & $7.8 \pm 0.2(37) \mathrm{DE}$ & $10.7 \pm 0.2(14) \mathrm{aF}$ & $9.9 \pm 0.1(13) b F$ & $18.7 \pm 0.3(14) \mathrm{aE}$ & $17.2 \pm 0.2(13) \mathrm{bE}$ \\
\hline 30.0 & $7.4 \pm 0.1(41) \mathrm{E}$ & - & - & - & - \\
\hline
\end{tabular}

a): Mean \pm SE. Values in parentheses indicate sample sizes.

b): Values followed by the same small letter within a row are not significantly different by $t$-test $(P>0.05)$.

c): Values followed by the same capital letter within the same column are not significantly different by Tukey-Kramer test following $\operatorname{ANOVA}(P>0.05)$. 
males was significantly shorter than that for females at $15-27.5^{\circ} \mathrm{C}$ ( $t$-test: for $15^{\circ} \mathrm{C}, t=4.720, \mathrm{df}=27, P<0.001$; for $17.5^{\circ} \mathrm{C}, t=8.291$, df $=29, P<0.001$; for $20^{\circ} \mathrm{C}, t=$ $4.865, \mathrm{df}=34, P<0.001$; for $22.5^{\circ} \mathrm{C}, t=5.077, \mathrm{df}=31, P$ $<0.001$; for $25^{\circ} \mathrm{C}, t=6.930$, df $=61, P<0.001$; and for $\left.27.5^{\circ} \mathrm{C}, t=3.284, \mathrm{df}=25, P=0.003\right)$. The total developmental time from oviposition to adult emergence was significantly shorter in males than in females at $17.5-27.5^{\circ} \mathrm{C}$ ( $t$-test: for $17.5^{\circ} \mathrm{C}, t=4.478, \mathrm{df}=29, P<0.001$; for $20^{\circ} \mathrm{C}$, $t=4.831, \mathrm{df}=34, P<0.001$; for $22.5^{\circ} \mathrm{C}, t=5.481, \mathrm{df}=$ $31, P<0.001$; for $25^{\circ} \mathrm{C}, t=7.888, \mathrm{df}=61, P<0.001$; and for $27.5^{\circ} \mathrm{C}, t=4.469$, df $=25, P<0.001$ ), except for that at $15^{\circ} \mathrm{C}(t$-test: $t=0.462, \mathrm{df}=27, P=0.648)$.

The linear regression equation for the developmental rate against temperature in C. concinnata was determined (Table 3). For the linear regression analysis, the developmental rate at $30^{\circ} \mathrm{C}$ was excluded because no adult emerged. The correlation of regression equations for each developmental stage was very high $\left(r^{2}>0.94, P<0.01\right)$. Based on the linear regression equations, the $T_{0}$ and $K$ were estimated.

\section{Body size and sex ratio of emerged adults}

For females, the mean puparial weight was largest at $15^{\circ} \mathrm{C}$ and decreased in a temperature-dependent manner (Table 4). For males, the mean puparial weight was not significantly different among the temperatures 17.5 $27.5^{\circ} \mathrm{C}$, but was significantly larger at $15^{\circ} \mathrm{C}$ than others. The puparial weights of females were significantly larger than those of males at the same temperatures $(t$-test: for $15^{\circ} \mathrm{C}, t=7.362, \mathrm{df}=27, P<0.001$; for $17.5^{\circ} \mathrm{C}, t=7.518$, df $=29, P<0.001$; for $20^{\circ} \mathrm{C}, t=13.020, \mathrm{df}=34, P<$ 0.001 ; for $22.5^{\circ} \mathrm{C}, t=11.860, \mathrm{df}=31, P<0.001$; for $25^{\circ} \mathrm{C}$, $t=14.994$, df $=61, P<0.001$; and for $27.5^{\circ} \mathrm{C}, t=5.683$, $\mathrm{df}=25, P<0.001)$. The proportions of females in emerged adults at different temperatures varied from 0.33 to 0.57 at $15-27.5^{\circ} \mathrm{C}$, but the difference was not significant $\left(\chi^{2}\right.$ test: $\chi^{2}=6.813$, df $\left.=6, P=0.235\right)$.

\section{Discussion}

The present study shows that $C$. concinnata females laid one egg per single ovipositional attack in many cases,

Table 3. The linear regression equation, lower developmental threshold and total effective temperature for $C$. concinnata

\begin{tabular}{lcccccc}
\hline \hline Developmental stage & Sex & $\begin{array}{c}\text { Linear regression } \\
\text { equation) }\end{array}$ & $P$ & $r^{2}$ & $\begin{array}{c}\text { The lower } \\
\text { developmental } \\
\text { threshold }\left(T_{0}\right) \\
\left({ }^{\circ} \mathrm{C}\right)\end{array}$ & $\begin{array}{c}\text { Total effective } \\
\text { temperature }(K) \\
(\text { degree-days })\end{array}$ \\
\hline Eggs and Larvae & & $\mathrm{Y}=0.007 \mathrm{X}-0.056$ & 0.0012 & 0.944 & 8.0 & 169.4 \\
Puparia & Female & $\mathrm{Y}=0.005 \mathrm{X}-0.040$ & $<0.0001$ & 0.988 & 8.0 & 221.9 \\
& Male & $\mathrm{Y}=0.005 \mathrm{X}-0.044$ & $<0.0001$ & 0.990 & 8.8 & 185.4 \\
Oviposition-adult emergence & Female & $\mathrm{Y}=0.003 \mathrm{X}-0.023$ & 0.0001 & 0.979 & 7.7 & 404.4 \\
& Male & $\mathrm{Y}=0.003 \mathrm{X}-0.026$ & 0.0001 & 0.977 & 8.7 & 342.1 \\
\hline
\end{tabular}

a): Linear regression analysis was applied to the developmental data within $15-27.5^{\circ} \mathrm{C}$.

Table 4. Puparial weights and sex ratios of $C$. concinnata at seven temperatures

\begin{tabular}{cccc}
\hline \hline \multirow{2}{*}{$\begin{array}{c}\text { Temperature } \\
\left({ }^{\circ} \mathrm{C}\right)\end{array}$} & \multicolumn{2}{c}{ Puparial weight $(\mathrm{mg})^{\mathrm{a})}$} & $\begin{array}{c}\text { Proportion of females } \\
\text { in emerged adults }{ }^{\mathrm{b})}\end{array}$ \\
\cline { 2 - 3 } 15.0 & $60.4 \pm 1.4(11) \mathrm{aA}$ & $45.3 \pm 1.3(18) \mathrm{bA}$ & 0.38 \\
17.5 & $52.8 \pm 1.9(13) \mathrm{aB}$ & $36.3 \pm 1.3(18) \mathrm{bB}$ & 0.42 \\
20.0 & $51.4 \pm 1.2(12) \mathrm{aBC}$ & $34.3 \pm 0.7(24) \mathrm{bB}$ & 0.33 \\
22.5 & $50.3 \pm 1.2(15) \mathrm{aBC}$ & $35.6 \pm 0.5(18) \mathrm{bB}$ & 0.45 \\
25.0 & $47.6 \pm 0.7(36) \mathrm{aCD}$ & $32.9 \pm 0.7(27) \mathrm{bB}$ & 0.57 \\
27.5 & $44.4 \pm 1.6(14) \mathrm{aD}$ & $33.9 \pm 0.8(13) \mathrm{bB}$ & 0.52 \\
30.0 & - & - & - \\
\hline
\end{tabular}

a): Mean \pm SE. Values in parentheses indicate sample sizes. Values followed by the same small letter within the same row are not significantly different by t-test $(P>0.05)$. Values followed by the same capital letter within the same column are not significantly different by Tukey-Kramer test following ANOVA $(P>0.05)$.

b): There was no significant difference in sex ratios among the seven temperatures by $x^{2}$ test $(P>0.05)$. 
but occasionally laid more than one egg at a time (Fig. 1). Additionally, the females often deposit no eggs even though they attacked the hosts. Lepidopteran caterpillars often attempt to protect themselves against parasitoids by behavioural and/or morphological defenses ${ }^{10}$. Many of the hosts have characteristics such as head-flicking and thrashing behaviour to deter parasitoids from attacking them ${ }^{10}$. Larvae of M. separata are also known to show aggressive behaviour which dislodge or bite tachinid eggs with their mandibles ${ }^{23}$. In this study, we frequently observed the M. separata larvae flick their heads and vomit saliva toward the females of $C$. concinnata during attacks. Therefore, we hypothesized that an attack without oviposition was caused by the defense behavior of the host. Contrary to our expectation, imperfect oviposition occurred when host movement was arrested. The reasons for this phenomenon remain unclear at this time, but it might be due to the function of the female reproductive system of C. concinnata.

Compsilura concinnata successfully developed from egg to adult throughout a temperature range of 15.0$27.5^{\circ} \mathrm{C}$ (Table 1). At $30^{\circ} \mathrm{C}$, the highest temperature tested, this fly was able to pupariate but not able to emerge as an adult. When the puparia egressed at $30^{\circ} \mathrm{C}$ were dissected later, the majority of the dead flies were in the form of adults inside puparia. Most likely, C. concinnata almost completes the metamorphosis into an adult and then dies without emerging from the puparium at $30^{\circ} \mathrm{C}$. Thus, $30^{\circ} \mathrm{C}$ or more appears to be unsuitable for the pupal development of $C$. concinnata. Fusco et al. ${ }^{9}$ also found that this tachinid failed to emerge at $32.3^{\circ} \mathrm{C}$, when $L$. dispar larvae were used as a host. They reported that this tachinid developed successfully within a temperature range of $15.6-29.4^{\circ} \mathrm{C}$.

The developmental times and body size of C. concinnata were affected by temperature in both sexes, while sex ratios of emerged adults were not affected by temperature (Tables $2 \& 4$ ). It is generally known that females are larger than males in some tachinids ${ }^{17,20}$. In our study, as well, the body size of females was significantly larger than that of males (Table 4). Also, the results from our experiments suggest that males tended to emerge a few days earlier than the females (Table 2). Early emergence of males is also known in other tachinids ${ }^{4,5,15,17,21,26}$.

In this study, the $T_{0}$ from the time of oviposition to adult emergence of $C$. concinnata was estimated to be 7.7 for females and 8.7 for males. Also, the $K$ from oviposition to adult emergence was estimated at 404.4 for females and 342.1 for males (Table 3). According to Hirai and Santa ${ }^{13}$, the $T_{0}$ and $K$ from oviposition to adult emergence of M. separata were 7.1 and 736.6, respectively. Generally, the $T_{0}$ of parasitoids have a higher value than that of their hosts $^{3,18}$, while $K$ values are lower for parasitoids than for hosts $^{18}$. The results obtained in this study were consistent with this rule.

From the values of $T_{0}$ and $K$ obtained in this study, we assumed that $C$. concinnata occurs several times from early spring to late autumn. C. concinnata, which can parasitize over 200 different host species, probably utilizes not only M. separata but also various host species through its generations in the field. Recently, severe damage by $C$. concinnata, which has been introduced as a biological control agent against $L$. dispar, was reported on populations of native and non-target lepidopteran species in North America ${ }^{2,14,19}$. Boettner et al. ${ }^{2}$ reported that $C$. concinnata and its parasitism likely resulted in a significant decline in native silk moths. As L. dispar is univoltine $^{8}$, this parasitoid would attack non-target species to complete multiple generations each year after $L$. dispar larvae are no longer available ${ }^{2,14,19}$. In the present study, C. concinnata showed high survival rates throughout a wide temperature range of $15.0-27.5^{\circ} \mathrm{C}(73.0-92.9 \%)$ when M. separata was used as the host (Table 1). Assuming there is a high probability that this tachinid can parasitize many other lepidopteran species as in the case of $M$. separata, there is a possibility that the impact of $C$. concinnata on native species may increase. To evaluate the parasitization ability of $C$. concinnata, it is necessary to further investigate its immature development and survival using several other lepidopterans as the host.

\section{Acknowledgments}

We express our thanks to Dr. H. Shima, Dr. Y. Nakahara and Dr. T. Tachi for their valuable comments and advice. We also thank Dr. T. Noda for providing the experimental devices and Ms. C. Yokokura for her technical assistance. This work was supported by a Research Fellowship (to R. Ichiki) through the Japan Society for the Promotion of Science (JSPS).

\section{References}

1. Arnaud, P. H. Jr. (1978) A host-parasite catalog of North American Tachinidae (Diptera). Misc. Publ. US Dep. Agric., 1319, 1-860.

2. Boettner, G. H., Elkinton, J. S. \& Boettner, C. J. (2000) Effects of a biological control introduction on three nontarget native species of saturniid moths. Conserv. Biol., 14, 1798-1806.

3. Campbell, A. et al. (1974) Temperature requirements of some aphids and their parasites. J. Appl. Ecol., 11, 431-438.

4. Cardoza, Y. J., Epsky, N. D. \& Heath, R. R. (1997) Biology and development of Lespesia aletiae (Diptera: Tachinidae) in two Lepidopteran species in the laboratory. Fla. 
Entomol., 80, 289-300.

5. Chauthani, A. R. \& Hamm, J. J. (1967) Biology of the exotic parasite Drino munda (Diptera: Tachinidae). Ann. Entomol. Soc. Am., 60, 373-376.

6. Coulson, J. R. et al. (1986) Exploration for and importation of natural enemies of the gypsy moth, Lymantria dispar (L.) (Lepidoptera: Lymantriidae), in North America: an update. Proc. Entomol. Soc. Wash., 88, 461-475.

7. Culver, J. J. (1919) A study of Compsilura concinnata, an imported tachinid parasite of the gypsy moth and the brown-tail moth. Bull. US Bur. Entomol., 766, 1-27.

8. Furuta, K. (1973) Developmental zero temperature and effective thermal constant in Lymantria dispar collected from Sapporo, Hokkaido. Forest Pests, 22, 120-123 [In Japanese].

9. Fusco, R. A., Rhoads, L. D. \& Blumenthal, M. (1978) Compsilura concinnata: effect of temperature on laboratory propagation. Environ. Entomol., 7, 15-18.

10. Gross, P. (1993) Insect behavioral and morphological defenses against parasitoids. Annu. Rev. Entomol., 38, 251-273.

11. Hattori, M. \& Atsusawa, S. (1980) Mass-rearing of the cabbage armyworm, Mamestra brassicae Linné and the common armyworm, Mythimna separata Walker (Lepidoptera: Noctuidae) on a simple artificial diet. Jpn. J. Appl. Entomol. Zool., 24, 36-38 [In Japanese with English summary].

12. Herting, B. (1960) Biologie der westpaläarktischen Raupenfliegen Dipt., Tachinidae. Monogr. Angew. Entomol., 16, 1-188.

13. Hirai, K. \& Santa, H. (1983) Comparative physio-ecological studies on the armyworms, Pseudaletia separata Walker and Leucania loreyi Duponchel (Lepidoptera: Noctuidae). Bull. Chugoku Agric. Exp. Stn. Ser. E, 21, 55-101 [In Japanese with English summary].

14. Howarth, F. G. (2000) Non-target effects of biological control agents. In Biological control: Measures of success, eds. Gurr, G. \& Wratten, S., Kluwer Academic Publishers, Dordrecht, 369-403.

15. Hughes, P. S. (1975) The biology of Archytas marmoratus (Townsend). Ann. Entomol. Soc. Am., 68, 759-767.

16. Ichiki, R. \& Shima, H. (2003) Immature life of Compsilura concinnata (Meigen) (Diptera: Tachinidae). Ann. Entomol. Soc. Am., 96, 161-167.

17. Ichiki, R., Takasu, K. \& Shima, H. (2003) Effects of temperature on immature development of the parasitic fly Bessa parallela (Meigen) (Diptera: Tachinidae). Appl. Entomol. Zool., 38, 435-439.

18. Kiritani, K. (1997) The low development threshold temperature and the thermal constant in insects, mites and nematodes in Japan. Misc. Publ. Nat. Inst. Agr. Sci., 21, 1-72 [In Japanese with English summary].

19. Louda, S. M. et al. (2003) Nontarget effects-The Achilles' heel of biological control? Retrospective analyses to reduce risk associated with biocontrol introductions. Annu. Rev. Entomol., 48, 365-396.

20. Miles, L. R. \& King, E. G. (1975) Development of the tachinid parasite, Lixophaga diatraeae, on various developmental stages of the sugarcane borer in the laboratory. Environ. Entomol., 4, 811-814.

21. Nakamura, S. (1994) Parasitization and life history parameters of Exorista japonica (Diptera: Tachinidae) using the common armyworm, Pseudaletia separata (Lepidoptera: Noctuidae) as a host. Appl. Entomol. Zool., 29, 133-140.

22. Nakamura, S. (1995) Optimal clutch size for maximizing reproductive success in a parasitoid fly, Exorista japonica (Diptera: Tachinidae). Appl. Entomol. Zool., 30, 425-431.

23. Nakamura, S. (1997) Ovipositional behaviour of the parasitoid fly, Exorista japonica (Diptera: Tachinidae), in the laboratory: diel periodicity and egg distribution on a host. Appl. Entomol. Zool., 32, 189-195.

24. Shima, H. (1984) Study on the tribe Blondeliini from Japan (Diptera, Tachinidae). V. the genera Blondelia Robineau-Desvoidy and Compsilura Bouché. Kontyû, Tokyo, 52, 540-552.

25. Shima, H. (2006) A host-parasite catalog of Tachinidae (Diptera) of Japan. Makunagi/Acta Dipterologica, Suppl. 2, 1-171.

26. Webber, R. T. (1932) Sturmia inconspicua Meigen, a tachinid parasite of the gipsy moth. J. Agric. Res., 45, 193-208. 